\title{
Photophysical and Photochemical Properties of Green Fluorescent Liquid Crystalline Systems
}

\author{
Ivo Grabchev and Jean-Marc Chovelon ${ }^{\mathrm{a}}$ \\ Institute of Polymers, Bulgarian Academy of Sciences, 1113 Sofia, Bulgaria \\ ${ }^{a}$ Université Claud Bernard - Lyon 1, Laboratoire d'Application de la Chimie à l'Environnement \\ (LACE), CNRS - UMR 5634, 43, boulevard du 11 november 1918, F-69622 Villeurbanne Cedex \\ Reprint requests to Prof. I. G.; E-mail: grabchev@ polymer.bas.bg
}

Z. Naturforsch. 58a, 45-50 (2003); received November 26, 2001

\begin{abstract}
The photophysical properties of polymer-dispersed liquid crystal systems, containing naphthalimide dye as fluorescent units are reported. Investigations have been carried out on some 1,8naphtalimide derivatives both in isotropic and anisotropic media, and their photophysal properties have been described. The orientational order parameters of the dyes in nematic liquid crystal ZLI 1840 have been determined. The photostability of the dye/liquid crystal systems has been investigated and the effect that the substituents in the naphthalimide structure have upon the orientation of the dye was discussed.
\end{abstract}

Key words: Liquid Crystal Display; Polymer-dispersed Liquid Crystal; 1,8-naphthalimide Dyes; Photodegradation; Photophysics.

\section{Introduction}

During the recent years, coloured liquid crystal systems (LC's) for utilisation in electro-optical devices have intensively been investigated [1]. Fluorescent coloured liquid crystal displays of the "guest-host" type are built up of a nematic LC and dichtoic dyes dissolved therein. The introduction of polymeric components into the LC results in enhanced self-support of display systems [2, 3]. Displays of the guest-host type can work in active and passive modes and need only one polarizer [4]. Though the choice of suitable dyes is among the basic problems for practical utilisation of such LC displays.

With their photophysical properties, 1,8-naphthalimide dyes are able to meet the requirements for LC display colorants. These dyes exhibit good dichroism and orientation in the liquid crystal matrix [5 - 7]. Some of them have been reported to improve the display image contrast over a large viewing angle [4]. On the other hand, the 1,8-naphthalimide dyes have an excellent yellow colour, emit green fluorescence and are photostable in organic solvents and polymer matrices [8 - 10]. Blue and green fluorescent copolymers with 1,8-naphthalimide side-group have been examined in liquid crystal matries [11 - 13].
In this work we report on investigations of some properties of dye / liquid crystal (ZLI 1840 systems and ZLI 1840 / polymethylmetacrylate, PMMA) systems with regard of their potential application in guest-host liquid crystal displays. The utility of the new systems for colouring LC displays is discussed on the basis of their photophysical properties and on the effect that dyes have upon the orientation order parameter in surface stabilised display cells determined by polarised absorption and fluorescense spectroscopy. The photostability of coloured LC systems has also been investigated.

\section{Experimental}

The 1,8-naphthalimide derivatives investigated as a "guest" have the following structure<smiles>[R]c1ccc2c3c(cccc13)C(=O)N([Y])C2=O</smiles>

in which the substituents $\mathrm{A}$ and $\mathrm{R}$ are: 


\begin{tabular}{lllr}
\hline DyeA & $\mathrm{R}$ & Ref. \\
\hline $1 \mathrm{CH}_{2} \mathrm{CH}=\mathrm{CH}_{2}$ & $\mathrm{NHCH}_{2} \mathrm{CH}_{2} \mathrm{CH}_{2} \mathrm{CH}_{3}$ & {$[14]$} \\
2 & $\mathrm{CH}_{2} \mathrm{CH}=\mathrm{CH}_{2}$ & $\mathrm{NHCH}_{2} \mathrm{CH}_{2} \mathrm{CH}_{2} \mathrm{CH}_{2} \mathrm{CH}_{2} \mathrm{CH}_{3}[14]$ \\
$3 \mathrm{CH}_{2} \mathrm{CH}_{2} \mathrm{CH}_{2} \mathrm{CH}_{3}$ & $\mathrm{NHCH}_{2} \mathrm{CH}_{2} \mathrm{CH}_{2} \mathrm{CH}_{3}$ & {$[15]$} \\
4 & $\mathrm{CH}_{2} \mathrm{CH}_{2} \mathrm{CH}_{2} \mathrm{CH}_{2} \mathrm{CH}_{2} \mathrm{CH}_{3} \mathrm{NHCH}_{2} \mathrm{CH}_{2} \mathrm{CH}_{2} \mathrm{CH}_{2} \mathrm{CH}_{2} \mathrm{CH}_{3}[15]$ \\
\hline
\end{tabular}

Polymethylmethacrylate (PMMA) with molecular weight characteristics described in [10] was used as a polymer for the preparation of polymer-dispersed liquid crystal (PDLC) systems. The liquid crystalline mixture ZLI 1840, supplied by MERCK (Darmstat, Germany), was used as host. It exhibits a stable nematic phase over a broad temperature range $(-15$ to $90{ }^{\circ} \mathrm{C}$ ) [16]. The dyes were initially screened for solubility in the LC. For further studies, the dyes were dissolved to a concentration of 0.5 wt. \% $\left(1.610^{-2} \mathrm{M}\right)$, which was suitable for the spectroscopic evaluation of the order parameter and simultaneously guaranteed an appropriate constant ratio [17]. Dye/LC and Dye/LC/PMMA mixtures were studied in "sandwich" cells of $20 \mu \mathrm{m}$ thickness. The mixtures formed thin oriented layers between two glass plates with an area of $2 \times 3 \mathrm{~cm}$. The uniform planar orientation of the Dye/LC systems was achieved by coating the cell surfaces with polyvinyl alcohol layers that were additionally rubbed. The orientation order parameters of the dyes dissolved in the LC were evaluated from the polarised components of absorption and fluorescence spectra. Neutral UV polarisers were used both for the absorption and fluorescence measurements.

Composite films Dye/LC/PMMA were prepared by the SIPS (solvent induced phase separation) technique [2], using chloroform as a solvent. The 10:90 PMMA: dye/LC mixtures were chosen to explore the stabilising effect of the PMMA component upon the systems. Films, $20 \mu \mathrm{m}$ thick, were casted from chloroform solution of all the components onto glass plates at room temperature. The obtained films were selfsupported, a fact showing their perfect appropriatness for applications in a large area and for flexible displays.

UV-Vis spectrophotometric investigations of the coloured LC systems were performed on a UVIKON 930 spectrophotometer (KONTRON instruments). The fluorescence spectra were taken on an SFM 25 spectrophotometer (KONTRON instruments).

The fluorescence quantum yield of the dyes was determined on the basis of the absorption and fluorescence spectra of the dye taken in ethanol. Rodamine $6 \mathrm{G}$ as standard $\left(\Phi_{\mathrm{F}}=0.88[18]\right)$ was used.
Table 1. Photophysical characteristics of dyes $1-4$ in ethanol.

\begin{tabular}{lcccc}
\hline & Dye 1 [14] & Dye 2 [14] & Dye 3 & Dye 4 \\
\hline$\lambda_{\mathrm{A}} / \mathrm{nm}$ & 440 & 438 & 442 & 442 \\
$\epsilon / 1 \mathrm{~mol}^{-1} \mathrm{~cm}^{-1}$ & 14500 & 12600 & 18300 & 22900 \\
$\lambda_{\mathrm{F}} / \mathrm{nm}$ & 525 & 523 & 521 & 521 \\
$\nu_{\mathrm{A}}-\nu_{\mathrm{F}} / \mathrm{cm}^{-1}$ & 3679 & 3710 & 3400 & 3400 \\
$\Phi_{\mathrm{F}}$ & 0.74 & 0.70 & 0.55 & 0.81 \\
\hline
\end{tabular}

A solar simulator (Sunthest CPS+, HERAEUS), equipped whit a $1.5 \mathrm{~kW}$ xenon arc lamp, protected whit an adequate filter to simulate the solar spectrum between 290 and $800 \mathrm{~nm}$, was used. The experiments were carried out in ordinary atmosphere at $20^{\circ} \mathrm{C}$.

\section{Results and Discussion}

\subsection{Photophysiacal Properties of 1,8-naphthal- imides in Isotropic and Anisotropic Media}

The photophysical properties of 1,8-naphthalimides depend basically on the polarisation of the naphthalimide molecule due to the electron donor-acceptor interaction occurring between the substituents at C-4 and the carbonyl groups from the imide structure of the chromophoric system. Table 1 presents the spectral characteristics of the 1,8-naphthalimide dye under study in ethanol solution: the absorption $\left(\lambda_{\mathrm{A}}\right)$ and fluorescence $\left(\lambda_{\mathrm{F}}\right)$ maxima, the extinction coefficient $(\varepsilon)$, Stokes shift $\left(\nu_{\mathrm{A}}-\nu_{\mathrm{F}}\right)$, and quantum yield of fluorescence $\left(\Phi_{\mathrm{F}}\right)$.

In ethanol solution, the dyes exhibit a yellowgreen colour with an absorption maximum at $\lambda_{\mathrm{A}}=$ 438 - $442 \mathrm{~nm}$ and intense fluorescence, whose maximum is situated at $\lambda_{\mathrm{F}}=521-525 \mathrm{~nm}$. In all cases the extinction coefficients $\varepsilon$ are higher than $12600 \mathrm{moll}^{-1} \mathrm{~cm}^{-1}$, indicating that the long-wavelength band of the absorption spectra is a band of charge transfer (CT), due to $\pi \rightarrow \pi^{*}$ electron transfer on $\mathrm{S}_{0} \rightarrow \mathrm{S}_{1}$ transition. The Stokes shift is a parameter which indicates the difference in the properties and structure of the dyes between the ground state $S_{0}$ and the first exited state $S_{1}$. The Stokes shifts are in the $3400-3710 \mathrm{~cm}^{-1}$ region, which is in accordance with other our investigations on the 1,8-naphthalimide derivatives [7 - 10]. The fluorescence efficiency of 1,8-naphthalimides is estimated by measuring their quantum yield $\Phi_{\mathrm{F}}$ on the basis of the absorption and fluorescence spectra. As seen from the data in Table 1, the 1,8-naphthalimide dyes studied have a high quantum yield $\Phi_{\mathrm{F}}=0.55-0.81$. 
Table 2. Photophysical characteristics of dyes 1 - 4 in nematic liquid crystal ZLI 1840.

\begin{tabular}{lcccc}
\hline & Dye 1 & Dye 2 & Dye 3 & Dye 4 \\
\hline$\lambda_{\mathrm{A}} / \mathrm{nm}$ & 433 & 431 & 431 & 430 \\
$\epsilon / 1 \mathrm{~mol}^{-1} \mathrm{~cm}^{-1}$ & 17900 & 10100 & 16500 & 9440 \\
$\lambda_{\mathrm{F}} / \mathrm{nm}$ & 493 & 493 & 493 & 493 \\
$\delta_{\mathrm{A}} / \mathrm{nm}$ & 71 & 66 & 75 & 73 \\
$\delta_{\mathrm{F}} / \mathrm{nm}$ & 50 & 50 & 52 & 51 \\
$\nu_{\mathrm{A}}-\nu_{\mathrm{F}} / \mathrm{cm}^{-1}$ & 2810 & 2917 & 2917 & 2971 \\
$f$ & 0.298 & 0.158 & 0.295 & 0.157 \\
\hline
\end{tabular}

Table 2 presents the spectral characteristics of the dyes 1 - 4 in liquid crystal ZLI 1840. The absorption $\left(\lambda_{\mathrm{A}}\right)$ and fluorescence $\left(\lambda_{\mathrm{F}}\right)$ maxima, the extinction coefficient $(\varepsilon)$, Stokes shift $\left(\nu_{\mathrm{A}}-\nu_{\mathrm{F}}\right)$, the oscillator strength $(f)$, the absorption half-bandwidths $\left(\delta_{\mathrm{A}}\right)$ and the fluorescence half-bandwidths $\left(\delta_{\mathrm{F}}\right)$ are given. In LC all 1,8-naphthalimide dyes retain their yellowgreen colour sinse their absorption maxima are in the range $\lambda_{\mathrm{A}}=430-433 \mathrm{~nm}$. On the other hand, the fluorescence maxima are at $\lambda_{\mathrm{F}}=493 \mathrm{~nm}$. For all dye/LC mixtures a hypsochromical shift with respect to the maxima in ethanol solution has been observed. Stokes shifts in the region $2810-2971 \mathrm{~cm}^{-1}$ were observed. They are smaller than the values obtained in ethanol solution. That means that in the LC matrix the conformation change of the dye chromophoric system is less pronounced. The exact determination of the fluorescence efficiency for a dye embedded in an oriented matrix is, however, very difficult because many factors, including anisotropy, must be taken into account. The results obtained in ethanol solution show that the dyes have a high quantum efficiency and retain it in the LC matrix.

An important characteristic of the dyes is the oscillator strength $(f)$ which reveals the effective number of electrons whose transition from the ground to the excited state gives the absorption area of the spectrum. Values of the oscillator strength can be calculated using the equation [19]

$$
f=4.32 \cdot 10^{-9} \Delta \nu_{1 / 2} \varepsilon_{\max }
$$

where $\Delta \nu_{1 / 2}$ is the width of the absorption band (in $\mathrm{cm}^{-1}$ ) at $1 / 2 \varepsilon_{\max }$.

The values obtained for $f$ range from 0.157 to 0.298 . For the dyes 2 and 4, having a hexylamino group as a substituent at the $\mathrm{C}-4$ position, the $f$ values are lower. The highest values for dyes 1 and 3 correlate well with the hypochromic effect of the dyes in LC matrix.

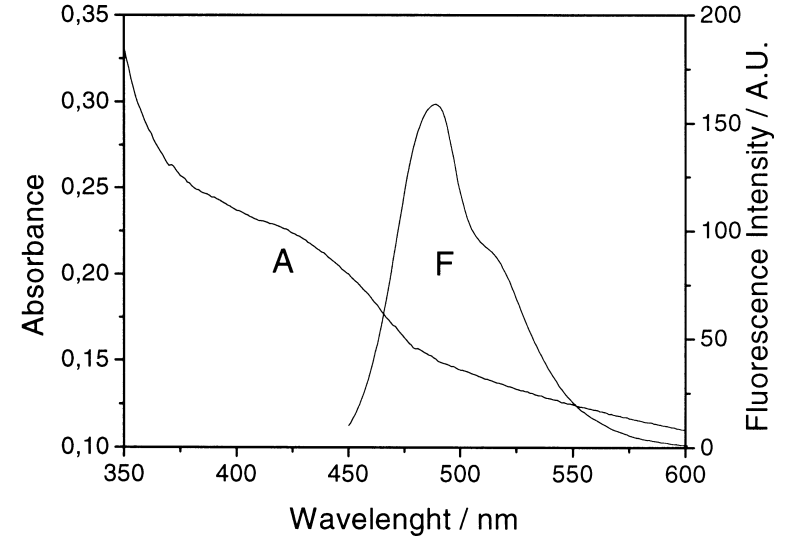

Fig. 1. Absorption (A) and fluorescence (F) spectra of dye 2 doped in PDLC system.

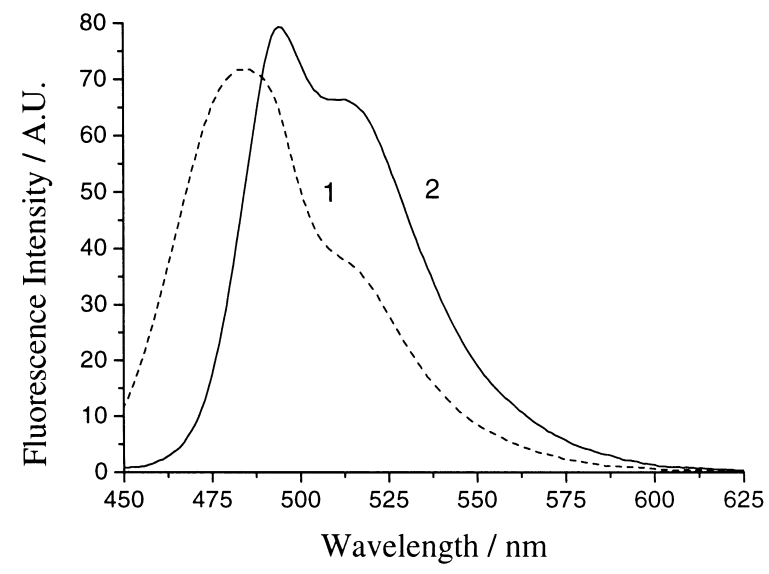

Fig. 2. Fluorescence spectra of dye1/LC/PMMA and dye $1 / \mathrm{LC}$.

The 1,8-naphthalimide derivatives 1 - 4 give a broad absorption $\left(\delta_{\mathrm{A}}=66-75 \mathrm{~nm}\right)$ band in the visible region, which suggests that the energy gap between the ground and excited state is very sensitive to the intermolecular interaction. The half-bandwidths in the fluorescence spectra are smaller: $\delta_{\mathrm{A}}>\delta_{\mathrm{F}}$.

Polymer - dispersed liquid crystals (PDLC) are a dispertion of LC micropores in a polymeric binder. It has been worth investigating the absorption and fluorescence property of these systems, containing 1,8-naphtalimide dyes as dyeing fluorescent units. Similar systems can be used as new materials in coloured electro-optical displays with large area, as light valves and temperature sensors, indicators etc. [20]. The properties of PDLC films depend on the nature of the LC and the polymer matrix, both. The 
dye/LC/PMMA mixtures are yellow-green coloured with intensive green fluorescence.

Figure 1 shows the absorption and fluorescense spectra of PDLC in the presence of dye 2. The absorption maximum is not very well pronounced because the liquid crystal microdroplets disperse the absorbed light. The fluorescence spectrum has a maximum at $485 \mathrm{~nm}$. It should be emphasized that all PDLC systems give almost the same fluorescent maxima at $\lambda_{\mathrm{F}}=$ 485 - $487 \mathrm{~nm}$. Figure 2 presents the fluorescence spectra of dye 1/LC and dye 1/LC/PMMA mixtures as examples. It is seen that, when the dyes and LC are dispersed into the polymer matrix, the fluorescent maxima are hypsochromically shifted. For all systems this shift is $\Delta \lambda=6-8 \mathrm{~nm}$.

\subsection{Ordering in Dye/Liquid Crystal Systems}

It has been found that substances added to a nematic LC affect its orientational order. Particularly convenient for measuring the orientation order parameters in LC systems involving dichroic dyes is the method based on polarized absorption or fluorescence spectroscopy. The orientation of the dyes in the "guest-host" LC systems depends on their molecular structure [1], concentration [21] and the molecular interactions between the molecules of the dye "guest" and LC "host" [22].

The orientational order parameter $S_{\mathrm{A}}$ of a dye in an LC can be calculated by measuring the polarized absorbancies at $\lambda_{\mathrm{A}}$ and utilising the equation [23, 24]

$$
S_{\mathrm{A}}=\frac{A_{\|}-A_{\perp}}{A_{\|}+2 A_{\perp}}\left(1-\frac{3}{2} \sin ^{2} \beta\right)^{-1} .
$$

Here, $A_{\|}$and $A_{\perp}$ are the corresponding absorbancies at $\lambda_{\max }$, at parallel and perpendicular orientation of the polariser according to the macroscopic orientation of the $\mathrm{LC}$, and $\beta$ is the angle between the long molecular axis of the dye and the direction of its absorption transition moment.

$$
\begin{aligned}
& \text { At } \beta=0,(2) \text { reduces to } \\
& \qquad S_{\mathrm{A}}=\left(A_{\|}-A_{\perp}\right) /\left(A_{\|}+2 A_{\perp}\right) .
\end{aligned}
$$

Dichroism measurements provide information on the orientation of the dye molecules in the LC matrix. The samples are dichroic, indicating that the dye-molecules are roughly aligned along the director, perpendicular to the surfaces.
Table 3. Absorption $S_{\mathrm{A}}$ and fluorescence $S_{\mathrm{F}}$ order parameters, and rate constant of photodegradation $K_{\mathrm{p}}$ of 1,8-naphthalimide dyes in nematic liquid crystal ZLI 1840.

\begin{tabular}{lcccc}
\hline & Dye 1 & Dye 2 & Dye 3 & Dye 4 \\
\hline$S_{\mathrm{A}}$ & 0.56 & 0.61 & 0.58 & 0.63 \\
$S_{\mathrm{F}}$ & 0.52 & 0.57 & 0.56 & 0.60 \\
$K_{\mathrm{p}} / \mathrm{s}^{-1} \times 10^{-5}$ & 8.71 & 9.23 & 9.70 & 10.64 \\
\hline
\end{tabular}

It is accepted that elongation of the dye molecule provides better orientation in LC. Table 3 summarizes the values of orientation order parameters obtained from the absorption and fluorescence measurements at $300 \mathrm{~K}$. As seen from the data presented, the substituents $A$ and $R$ affected the order parameter $S_{\mathrm{A}}$, the values varying in the range $0.56-0.63$. In the case of dye 2 and 4 the longest alkyl chains at C-4 position cause an increase the orientation order parameter which is related to the elongation of the dye molecules. Additionally, the substituent $A$ increases the orientation of dye molecules in LC.

Assuming that the lifetime of the excited state of the fluorescent dye is greater than the rotational correlation time, Baur et al. [25] have shown that the order parameter $S_{\mathrm{F}}$ of the dyes can also be calculated from the fluorescence measurements using the equation

$$
S_{\mathrm{F}}=\left(F_{\|}-F_{\perp}\right) /\left(F_{\|}+2 F_{\perp}\right) .
$$

The polarized fluorescence spectra of the "guest" 1,8naphthalimides have been taken in the LC in the same way as polarized absorption ones. $F_{\|}$and $F_{\perp}$ are the corresponding fluorescence intensities at $\lambda_{\max }^{\perp}$, with the polarisation direction parallel and perpendicular to the macroscopic orientation of the LC sample, respectively. Equation (4) is strictly valid only for the angle between the absorption and emission oscillators $\delta=0^{\circ}$.

The orientation order parameter $S_{\mathrm{F}}=0.52-0.60$ has been determined by the dye structure. Values lower than those obtained by polarized absorption spectrometry $S_{\mathrm{F}}<S_{\mathrm{A}}$ have been observed. These differences can be caused by: i) the existance of nonzero intramolecular angles between the absorption and emission oscillators, ii) intramolecular energy transfer processes which can depolarise the fluorescence in an unpredictable manner and lead to misinterpretation of the results, and iii) the interactions between the LC molecules and the cell surfase [26, 27]. 


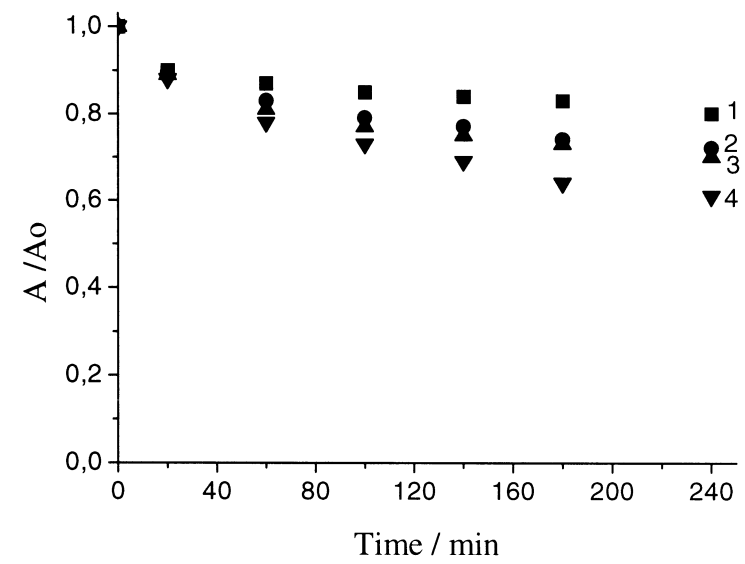

Fig. 3. Photodegradation of 1,8-naphthalimide dyes 1-4 in nematic liquid crystal ZLI 1840.

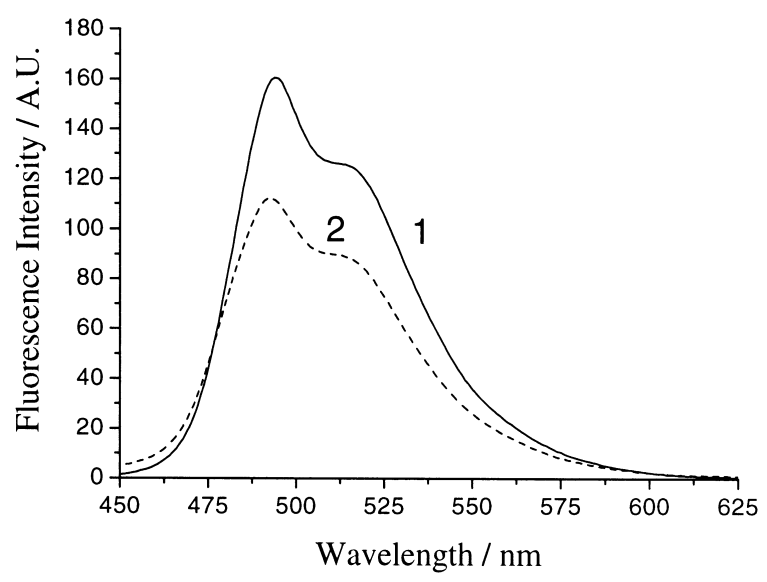

Fig. 4. Fluorescence intensity of dye 3 in nematic liquid crystal ZLI 1840 before, 1, and after, 2, irradiation.

\subsection{Photostability of Dye in Liquid Crystal Systems}

With regard for practical usage of the fluorescent LC systems it is worth studying their photostability in electro-optical display cells of $20 \mu \mathrm{m}$ thickness.

Figure 3 shows the dependence of absorption maxima of dye/LC systems on the irradiation time, and Table 3 lists the rate constants of the dye photodegradation. As seen, the degradation of coloured LC systems is most pronounced in the case of dyes 4 , which maybe due to the substituents $\mathrm{A}$ and $\mathrm{R}$. In this case

[1] A. Ivashenko and V. Rumiancev, Mol. Cryst. Liq. Cryst. 150A, 1 (1987).

[2] B. K. Kim, I. S. Ok, and C. H. Choi, J. Polym. Sci. Part B: Polym. Phys. 33, 707 (1995).

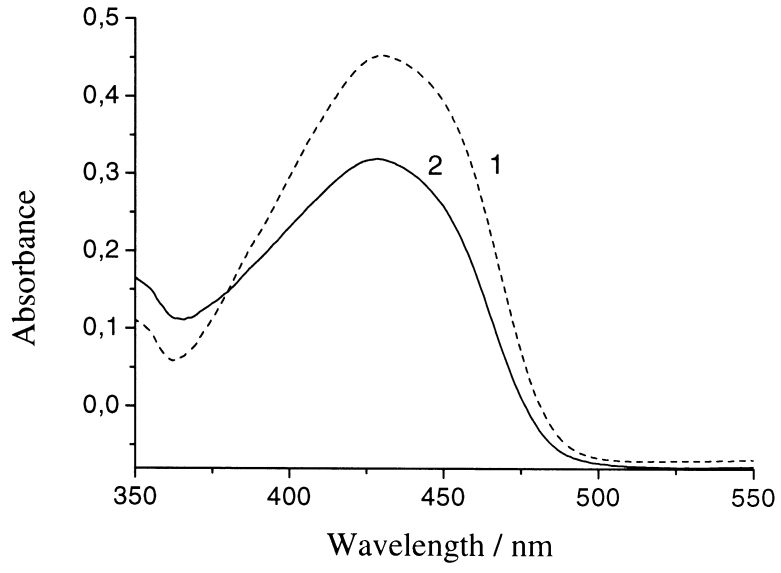

Fig. 5. Absorption spectra of dye 3 in the nematic liquid crystal ZLI 1840 before, 1, and after, 2, irradiation.

the longer substituents at both positions decrease the photostability. In general, the dyes degradation is not large and the photostability of the dye/LC system is good. Fluorescence intensity of the LC systems have been saved during the irradiation with minor diminuation, as seen from Figure 4. Before and after the irradiation there is not any change in the absorption maximum as well (Fig. 5).

\section{Conclusions}

In this paper the photophysical and photochemical studies on systems composed of the commercial nematic liquid crystal ZLI 1840 and 1,8-naphthalimide dyes are presented. The dyes have a yellow-green colour with intensive fluorescence both in ethanol solution and in LC matrix, and a good photostability. The colour and fluorescence emission are preserved in the polymer-dispersed liquid crystal systems wherein PMMA is used as a polymer. The results show that the 1,8-naphthalimide dyes investigated are suitable for applications as "guest" species in liquid crystal displays working in active and passive mode.

\section{Acknowledgement}

Ivo Grabchev expresses his gratitude to the NATO science program for a fellowship research grant.

[3] B. K. Kim, S. H. Kim, and C. H. Choi, Mol. Cryst. Liq. Cryst. 261, 605 (1995).

[4] E. Wolarz, H. Morison, and D. Bauman, Displays 13, 171 (1992). 
[5] D. Bauman, Skibinski, and R. Stolarski, Mol. Cryst. Liq. Cryst. 138, 367 (1986).

[6] K. Fiksinski, D. Bauman, Skibinski, and R. Stolarski, Dyes and Pigments 15, 203 (1991).

[7] I. Grabchev, I. Moneva, V. Bojinov, and S. Guittonneau, J. Mater. Chem. 10, 1291 (2000).

[8] I. Grabchev, T. Konstantinova, S. Guittonneau, and P. Meallier, Bull. Soc. Chem. Fr. 131, 828 (1994).

[9] I. Grabchev and V. Bojinov, Polym. Degrad. Stab. 70, 147 (2000).

[10] I. Grabchev and R. Betcheva, J. Photochem. Photobiol. A: Chem. 142, 73 (2001).

[11] G. Scherowsky, Macromol. Chem. Macromol. Symp. 69, 87 (1993).

[12] I. Grabchev, I. Moneva, E. Wolarz, and D. Bauman, Z. Naturforsch. 51a, 1185 (1995).

[13] I. Grabchev and I. Moneva, J. Appl. Polym. Sci. 74, 151 (1999).

[14] I. Grabchev, Ch. Petkov, and V. Bojinov, Dyes and Pigments 48, 239 (2001).

[15] S.-C. Chang, R. E. Utecht, and D. E. Lewis, Dyes and Pigments 43, 83 (1999).

[16] Merck prospect: Liquid Crystal Mixtures for Electrooptic Displays. Stuttgart, Germany: Merck AgaA October 1994.
[17] G. Gray, Chimia 34, 47 (1980).

[18] I. Olmstedt J. Phys. Chem. 83, 2581 (1979).

[19] P. Gordon and P. Gregory, Organic Chemistry in Colour, Moskva, Chimia, 1987 (in Russian)

[20] V. P. Shibaev, and L. Lam: Liquid Crystalline and Mezomorphic Polymers, in: Polymer Dispersed Liquid Crystal Films, G. P. Mongomery, Y. W. Smith, and N. A. Vaz, ed. Springer Verlag, New York 1994, pp. 149-192.

[21] W. Haase, O. Trinquet, U. Quotschalla, and J. Foitziik, Mol. Cryst. Liq. Cryst. 148, 15 (1987).

[22] D. Bauman, Mol. Cryst. Liq. Cryst. 158, 197, (1988).

[23] V. Rumiantsev, L. Blinov, and L. Kizel, Kristalografia 13, 1101 (1973)

[24] A. Ivashenko, O. Petrova, and O. Titov, Mol. Cryst. Liq. Cryst. 108, 51 (1984).

[25] G. Bauer, A. Stieb, and G. Meier, Mol. Cryst. Liq. Cryst. 22, 261 (1973).

[26] L. L. Chapoy, D. B. Du Pre, and E. Samulski, in: Liquid Crystals and Oriented Fluids, vol. 3, ed. F. F. Johanson and R. S. Porter, Plenum Press, New York 1978, p. 177.

[27] E. Wolarz, Z. Naturforsch. 47a, 807 (1992). 